\title{
Analisa Pergeseran Magnetic Domain Wall Pada Lapisan Tipis Free Layer CoFeB Untuk Sistem Spin-Valve Tunneling Magneto-Resistance (TMR) Sensor
}

\author{
Galih Setyawan, Edi Suharyadi* \\ Jurusan Fisika, Fakultas MIPA, Universitas Gadjah Mada, Yogyakarta, Indonesia \\ Sekip Utara PO BOX BLS. 21 Yogyakarta 55281, Indonesia \\ Corresponding Author : esuharyadi@ugm.ac.id
}

\begin{abstract}
Abstrak - Telah dilakukan analisa pergeseran magnetic domain wall pada lapisan tipis free layer CoFeB untuk sistem spinvalve Tunneling Magneto-Resistance (TMR). Analisa telah dilakukan dengan menggunakan software Object Oriented Micromagnetic Framework (OOMMF) berdasarkan persamaan Landau-Lifshitz Gilbert (LLG). Analisa pergeseran magnetic domain wall pada CoFeB yang mempunyai ukuran luas $120 \times 100 \mathrm{~nm}^{2}$ dengan variasi ketebalan 1 dan $4 \mathrm{~nm}$. Dari simulasi didapatkan hasil analisa pergeseran magnetic domain wall, histeresis loop dan energi dari sistem ferromagnetik (energy exchange dan demagnetisasi). Pada medan eksternal 299,9 Oersted CoFeB dengan ketebalan $1 \mathrm{~nm}$ nilai Mx/Ms adalah 0,99 dan pada ketebalan $4 \mathrm{~nm}$ nilai $\mathrm{Mx} / \mathrm{Ms}$ adalah 0.93. Energi demagnetisasi mempunyai pola naik dengan bertambahnya medan luar dan energi exchange menurun dengan bertambahnya medan luar.
\end{abstract}

Kata kunci: Pergeseran magnetic domain wall, Tunneling Magneto-Resistance (TMR), Simulasi mikromagnetik

Abstract - We have investigated the propagation of magnetic domain wall in a thin free layer CoFeB for spin-valve Tunneling Magneto-resistance (TMR) system. This analysis has been done by using micromagnetic simulation software Object Oriented Micromagnetic Framework (OOMMF) based on Landau-Lifshitz Gilbert (LLG). The propagation analysis of magnetic domain wall on $\mathrm{CoFeB}$ is $120 \times 100 \mathrm{~nm}^{2}$ of surface area with variational thickness 1 and $4 \mathrm{~nm}$. From this simulation, we gain the propagation of magnetic domain wall, hysterisis loop and energy from ferromagnetic system (energy exchange and demagnetisation). CoFeB, by the external field of 299,9 Oersted and $1 \mathrm{~nm}$ and $4 \mathrm{~nm}$ of thickness, has the Mx/Ms value of 0,99 and 0,93. This demagnetisation of energy has increasing of pattern by incresing of external field but contrary its proportional by the decresing of energy exchange.

Key words: Magnetic domain wall propagation, Tunneling Magneto-Resistance (TMR), micromagnetic simulation

\section{PENDAHULUAN}

TMR merupakan efek yang diakibatkan karena adanya arus tunneling pada lapisan isolator. Efek tunneling dipengaruhi oleh beberapa faktor, misalnya adalah ketebalan, tegangan dan suhu pada lapisan isolator [1].

TMR pertama kali ditemukan pada tahun 1975 oleh Julliere. TMR merupakan fenomena yang mempunyai kontribusi pada spintronic yang dapat digunakan untuk beberapa tujuan [2]. Contoh peranan TMR pada spintronic adalah untuk sensitive magnetic sensor dan microwave oscillator [3].

Penelitian pergeseran magnetic domain wall yang dilakukan pada penelitian ini adalah pada lapisan tipis CoFeB. Lapisan tipis CoFeB merupakan lapisan ferromagnetik yang dijadikan sebagai free layer untuk sistem spin-valve sensor TMR. Komposisi CoFeB dipilih karena mempunyai keunggulan tersendiri.

Lapisan CoFeB memiliki tekstur yang kuat (111), memiliki koersifitas dan $H_{f}$ yang lebih rendah bila dibandingkan dengan CoFe. Selain itu, hasil analisa komposisi kimia menunjukkan bahwa CoFeB lebih baik bila dibandingkan dengan $\mathrm{CoFe}$ [4].
Nanocrystalline atau amorphous pada lapisan tipis CoFeB sebelumny telah digunakan untuk spin-valve dan tunnel junction [4]. Jen dkk. (2006) mengatakan bahwa sifat GMR dan TMR dari bahan CoFeB sangat menarik perhatian dunia. Hal ini dikarenakan amorphous CoFeB mempunyai spin polarisasi yang tinggi atau dapat dikatakan memiliki nilai TMR yang tinggi pada suhu kamar [5]. Shinjo (2009) menyebutkan bahwa material Fe dan Co memiliki tunnel junction yang lebih tinggi dari pada material lain. Fe dan Co memiliki nilai tunnel junction sebesar 0.40 dan 0.35 [1].

Penelitian sebelumnya yang dilakukan pada lapisan CoFeB adalah melalui berbagai analisa, baik dengan TEM , MFM ataupun lainnya [5]. Penelitian pada lapisan tipis CoFeB dengan simulasi mikromagnetik adalah suatu yang belum dilakukan. Oleh karena itu, dalam penelitian ini akan disajikan hasil analisa simulasi pergeseran magnetic domain wall pada lapisan tipis CoFeB dengan menggunakan software OOMMF. Analisa akan dilakukan untuk histeresis loop dan analisa energi sistem ( energi exchange dan demagnetisasi). 


\section{METODE PENELITIAN}

Analisa pergeseran magnetic domain wall pada lapisan tipis CoFeB untuk sistem spin-valve TMR dilakukan dengan menggunakan software OOMMF. OOMMF merupakan software public yang dikembangkan oleh Mike Donahue dan Don Porter dari National Institute of Standards and Technology (NIST). Simulasi OOMMF berdasarkan pada persamaan LLG [6].

$\frac{d \boldsymbol{M}}{d t}=-\frac{\gamma}{\left(1+\alpha^{2}\right)}\left(\boldsymbol{M} \times \boldsymbol{H}_{\text {eff }}\right)-\frac{\gamma \alpha}{\left(1+\alpha^{2}\right) M} \boldsymbol{M} \times\left(\boldsymbol{M} \times H_{\text {eff }}\right)$

Ukuran sel idealnya adalah kurang dari perubahan panjang, perubahan panjang didefinisikan sebagai berikut :

$$
l_{\text {exchange }}=\sqrt{\frac{2 A}{\mu_{0} M_{S}^{2}}}
$$

Dengan $A$ dan $M s$ berturut-turut adalah konstanta exchange dan magnetik saturasi.

Pada simulasi variabel yang divariasikan dibatasi hanya pada ketebalan bahan CoFeB. Bahan CoFeB yang digunakan adalah berukuran 120x100 nm². Bahan CoFeB dengan ukuran 120x100 $\mathrm{nm}^{2}$ divariasikan ketebalannya sebesar 1 dan $4 \mathrm{~nm}^{2}$ dengan ukuran sel 2.5x2.5x $t \mathrm{~nm}^{3}(t=$ ketebalan). Parameter-parameter yang dimiliki oleh CoFeB dan digunakan sebagai input program adalah sebagai berikut:

$$
\begin{aligned}
M s & =1.16 \times 10^{6}[\mathrm{~A} / \mathrm{m}] \\
A & =1.37 \times 10^{-11}[\mathrm{~J} / \mathrm{m}] \\
\mathrm{K}_{\mathrm{u}} & =(1 / 20) \mathrm{MsHk}=1273\left[\mathrm{~J} / \mathrm{m}^{3}\right]
\end{aligned}
$$

Dengan $\mathrm{K}_{\mathrm{u}}$ adalah konstanta anisotropy bahan CoFeB.

Simulasi dilakukan dengan cara memberikan medan luar pada arah +x sebesar 300 Oe yang terdiri dari 150 step. Dengan adanya medan luar yang diberikan, diasumsikan akan adanya pergeseran magnetic domain wall mengikuti arah medan luar. Dinamika spin pada simulasi dapat dijelaskan dengan menggunakan persamaan (1). Desain Lapisan tipis CoFeB yang digunakan dalam eksperimen ditunjukkan pada Gambar 1. dan skema simulasi ditunjukkan pada Gambar 2.

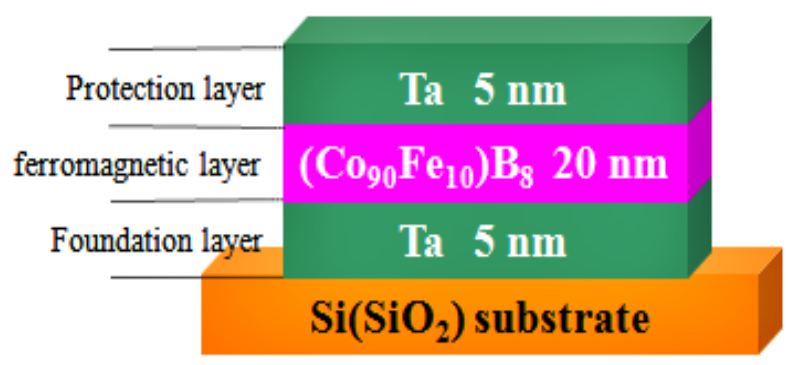

Gambar 1. Mikro-fabrikasi CoFeB dengan ukuran $20 x 20 \mu m^{2}$

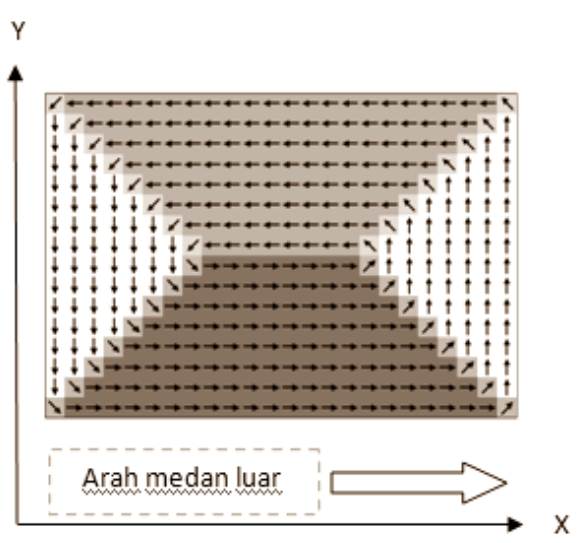

Gambar 2. Skema simulasi pemberian arah medan luar pada konfigurasi awal domain magnetik $\mathrm{CoFeB}$

\section{HASIL DAN PEMBAHASAN}

Hasil eksperimen histeresis loop pada lapisan tipis $\mathrm{CoFeB}$ dengan ukuran 20x20 $\mu^{2} \mathrm{~m}^{2}$ ketebalan $20 \mathrm{~nm}$ ditunjukkan pada Gambar 3.

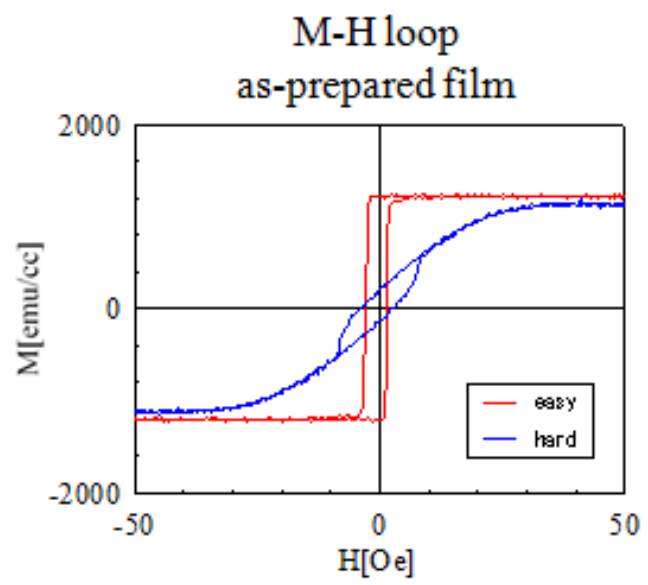

Gambar 3. Histeresis loop lapisan tipis CoFeB dengan ukuran 20x20 $\mu^{2}{ }^{2}$, ketebalan $20 \mathrm{~nm}$

Hasil histeresis loop yang dilakukan menunjukkan bahwa easy direction adalah pada in-plane dan hard direction pada arah out-plane. Hasil eksperimen ini digunakan sebagai dasar untuk melakukan simulasi pada arah in-plane.

Hasil simulasi switching field dapat dilihat pada Gambar 4. Hasil simulasi menunjukkan bahwa dengan bertambahnya ketebalan bahan, grafik loop akan semakin miring. Kemiringan loop mengindikasikan mudah tidaknya suatu bahan ferromagnetik untuk termagnetisasi dan tersaturasi.

Kemiringan loop dapat diketahui dengan menghitung gradien $\Delta y / \Delta x$ dari grafik histeresis loop. Kemiringan loop untuk ketebalan 1 dan $4 \mathrm{~nm}$ dibawah medan 100 Oe adalah 0,005 dan 0,002. Dengan bertambahnya ketebalan bahan, CoFeB akan lebih lambat termagnetisasi. Dari Gambar 4. setidaknya terdapat empat daerah bagian yang dapat 
diketahui. Daerah pertama (1) adalah daerah dimana magnetisasi meningkat secara perlahan, daerah kedua (2) daerah dimana terjadi penumbuhan magnetisasi secara cepat. Daerah tiga (3) menunjukkan rotasi dari magnetisasi untuk mencapai saturasi dan daerah empat (4) adalah saturasi.

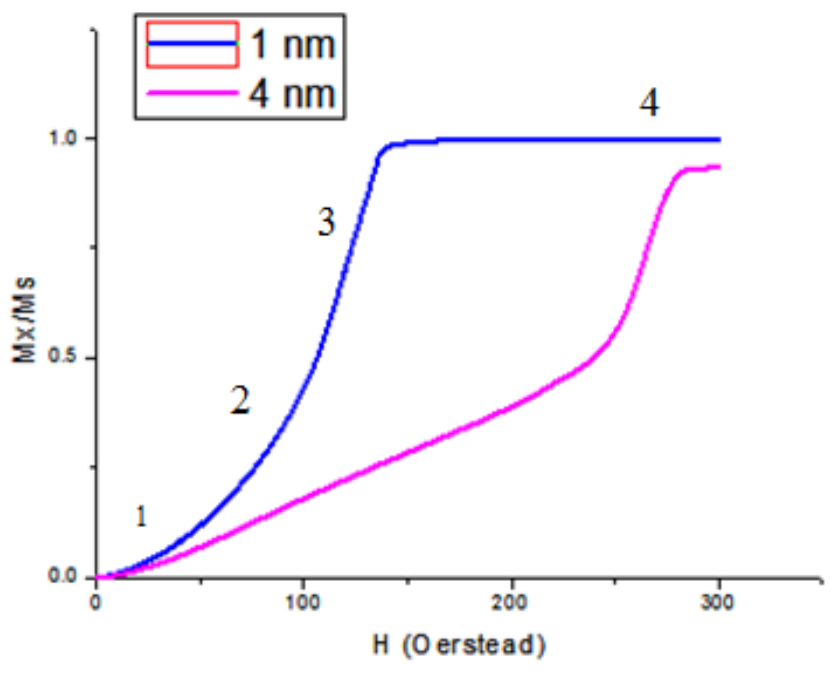

Gambar 4. Grafik histeresis loop Mx/Ms vs Medan Luar bahan CoFeB (120x100nm²) dengan ketebalan 1 dan $4 \mathrm{~nm}$
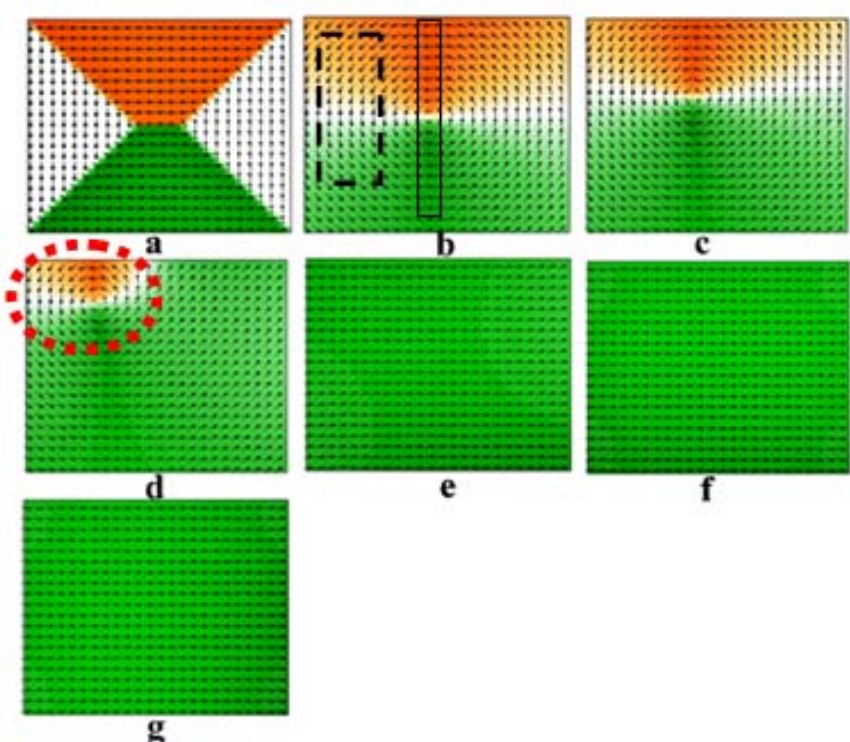

Gambar 5. Pola magnetik domain $\mathrm{CoFeB}$ dengan ketebalan 1 nm. a) 0 Oe, b) 40 Oe, c) 80 Oe, d) 120 Oe, e) 160 Oe, f) 250 Oe, g) $299,9 \mathrm{Oe}$

CoFeB dengan ketebalan $1 \mathrm{~nm}$ ditunjukkan pada Gambar 5. Gambar 5.a merupakan bentuk awal konfigurasi CoFeB sebelum diberikan medan luar. Konfigurasi menunjukkan CoFeB yang terdiri dari empat domain. Bentuk empat domain terjadi karena adanya interaksi exchange antara spin satu dengan yang lainnya. Arah magnetisasi mengikuti arah medan luar yang diberikan. Gambar 5.b memperlihatkan penyesuaian magnetisasi sesuai dengan medan luar yang membentuk vortek, sehingga terjadi perluasan domain magnetik pada arah (+)x. Terlihat bahwa terjadi perubahan arah spin secara gradual. Perubahan magnetik domain terdiri dari Bloch wall dan Nell wall. Konfigurasi Bloch wall ditunjukkan pada Gambar 5.b dengan tanda kotak hitam tegas, sedangkan konfigurasi Nell wall ditunjukkan dengan kotak hitam putus-putus. Konfigurasi ini juga berlaku untuk CoFeB dengan ketebalan $4 \mathrm{~nm}$ seperti pada Gambar 6 .

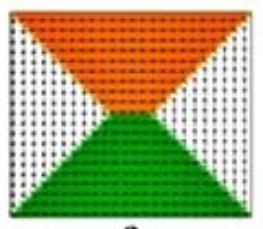

a

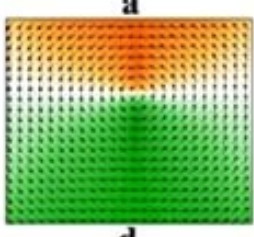

d

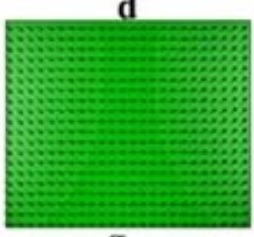

g
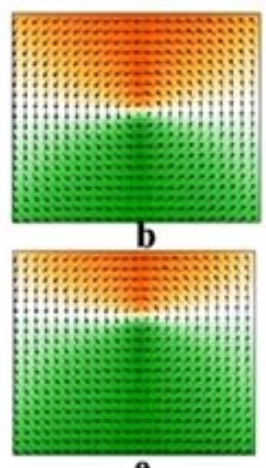

e
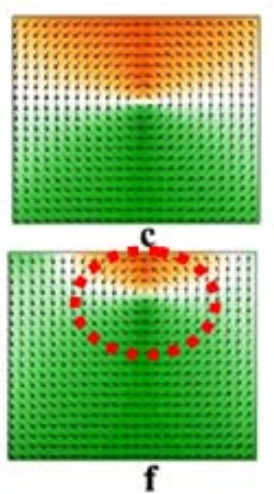

Gambar 6. Pola magnetik domain $\mathrm{CoFeB}$ dengan ketebalan 4 nm. a) 0 Oe, b) 40 Oe, c) 80 Oe, d) 120 Oe, e) 160 Oe, f) 250 Oe, g) $299,9 \mathrm{Oe}$

Ketika medan diberikan sebesar 120 Oe, magnetisasi berjalan cepat mencapai $\mathrm{Mx} / \mathrm{Ms}=0,70$ dari maksimal nilai 1 seperti yang ditunjukkan pada Gambar 5.d. Sedangkan CoFeB dengan ketebalan $4 \mathrm{~nm}$ dan medan yang sama, mempunyai nilai Mx/Ms sebesar 0,22. Hal ini membuktikan bahwa ketebalan mempengaruhi kecepatan dari magnetisasi. Perbedaan bentuk magnetisasi juga ditunjukkan pada Gambar 5.d dan Gambar 6.f. Gambar 5.d menunjukkan bentuk magnetisasi yang letaknya cenderung pada kiri atas, sedangkan Gambar 6.f letaknya cenderung di kanan atas. Hal ini bisa dipengaruhi oleh cepat lambatnya magnetisasi.

Pada medan 299,9 Oerstead CoFeB dengan ketebalan 1 dan $4 \mathrm{~nm}$ mempunyai nilai $\mathrm{Mx} / \mathrm{Ms}$ berturut-turut adalah sebesar 0,99 dan 0,93. Pada simulasi ini jika nilai maksimum spin angle lebih besar dibandingkan dengan energi exchange maka dapat diabaikan. Dari penelitian ditemukan bahwa kesalahan dapat ditoleransi apabila maksimum spin angle dibawah $45^{\circ}$. Pada awal simulasi juga ditemukan nilai $\mathrm{Mx} / \mathrm{Ms}$ bernilai negative, hal ini dikarenakan dot product $<\mathrm{M}$, e_x $><0$, dengan e_x adalah unit vector pada arah $+\mathrm{x}$.

Analisa energi dari sistem ferromagnetik juga dilakukan pada penelitian ini. Energi yang dianalisa adalah energi 
exchange dan energi demagnetisasi. Energi exchange yang merupakan energi yang timbul sebagai hasil interaksi antara spin dengan spin tetangga dengan fungsi medan luar ditunjukkan pada Gambar 7 . Gambar 7 menunjukkan bahwa energi exchange semakin menurun dengan bertambahnya medan luar. CoFeB dengan ketebalan $1 \mathrm{~nm}$ terlihat lebih cepat menurun bila dibandingkan CoFeB dengan ketebalan $4 \mathrm{~nm}$. Energi exchange menurun sebanding dengan termagnetisasinya magnetic domain wall CoFeB. Energi exchange menurun ketika interaksi antar spin tetangga semakin berkurang. Jika sudut antar spin berkurang, maka interaksi antar spin juga berkurang.

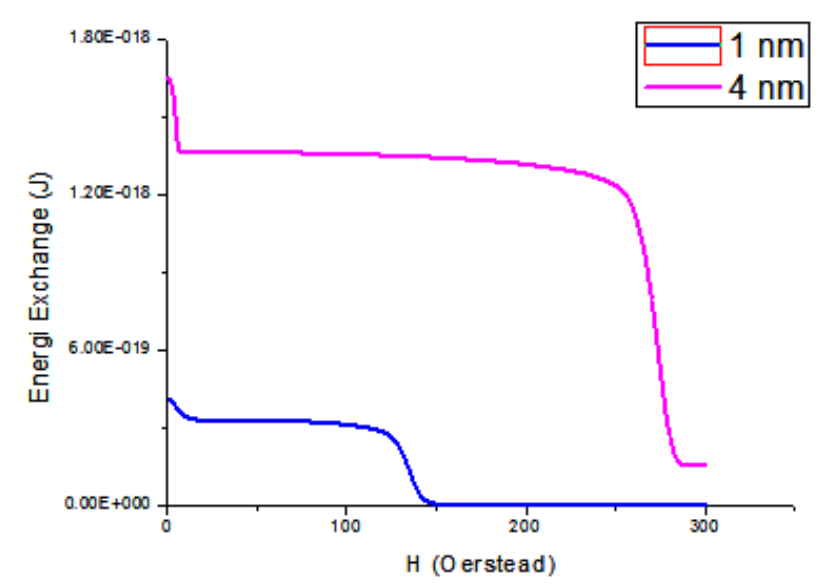

Gambar 7. Grafik hubungan energi exchange vs medan luar untuk CoFeB dengan ketebalan 1 dan $4 \mathrm{~nm}$

Berbeda dengan energi demagnetisasi yang ditunjukkan pada gambar 8. energi demagnetisasi yang merupakan hasil interaksi muatan yang berasal dari muatan itu sendiri terlihat naik dengan adanya penambahan medan magnet luar.

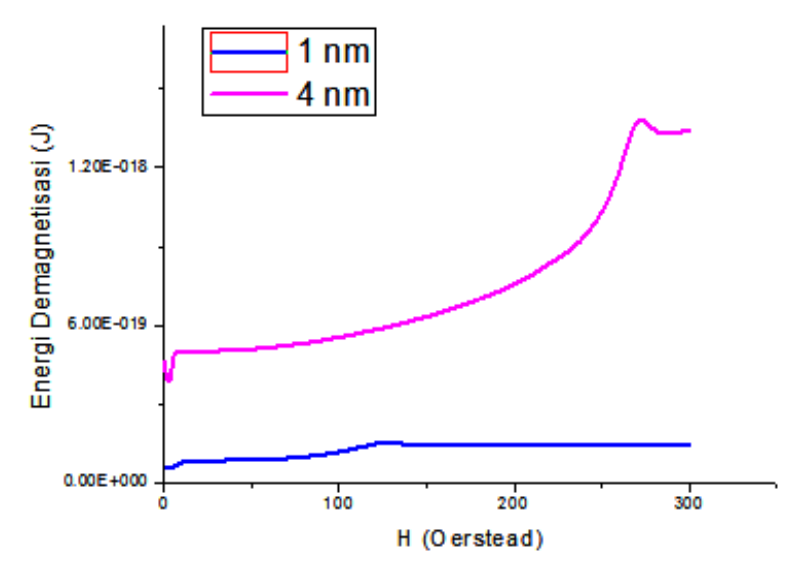

Gambar 8. Grafik hubungan energi demagnetisasi vs medan luar untuk CoFeB dengan ketebalan 1 dan $4 \mathrm{~nm}$

Gambar 8. menunjukkan energi demagnetisasi bahan CoFeB dengan ketebalan $4 \mathrm{~nm}$ lebih besar bila dibandingkan dengan ketebalan $1 \mathrm{~nm}$. Hal ini disebabkan karena dengan penambahan medan magnet luar, muatanmuatan dalam bahan juga berpengaruh yang mengakibatkan energi demagnetisasi meningkat.

\section{KESIMPULAN}

Pada penelitian ini dapat diketahui bahwa switching field dipengaruhi oleh ketebalan bahan CoFeB. Bahan CoFeB dengan ukuran $1 \mathrm{~nm}$ lebih cepat termagnetisasi bila dibandingkan dengan ketebalan $4 \mathrm{~nm}$. Magnetic domain wall bergeser dengan adanya penambahan medan luar. Energi exchange menurun dengan adanya penambahan medan luar, sedangkan energi demagnetisasi naik dengan adanya penambahan medan luar.

\section{PUSTAKA}

[1] T. Shinjo, Nanomagnetism and Spintronics, Elsevier, Oxford, 2009.

[2] W.H. Butler, Tunneling Magnetoresistance from a symmetry Filtering Effect, Science And Tecchnology of Advanced Matterials 8, 014106, 2008, (17pp).

[3] K. Sekiguci, T. Arakawa, Y. Yamauchi, K. chida, M. Yamada, et al., Observation of Full Shot Noise in $\mathrm{CoFeB} / \mathrm{MgO} / \mathrm{CoFeB}$-based magnetic Tunneling Junction, Applied Physics Letters 96, 2010, 252504.

[4] S. Cardoso, R. Ferreira, P.P. Freitas, J.O. Ventura, J.B. Sousa, et al., Ferromagnetic Coupling Field Reduction in CoFeB Tunnel Junctions Deposits by Ion Beam, IEEE Transaction on Magnetics, vol.40, No.4, 2004.

[5] S.U. Jen, Y.O. Yao, Y.T. Chen, J.M.Wu, C.C. Lee, et al., Magnetic and Electrical Properties of amorphous CoFeB Film, Journal of Applied Physics, 99, 2006, 053701.

[6] M.J. Donahue, D.G. Porter, OOMMF User's Guide, 2002. Website: http://math.nist.gov/oommf, diakses tanggal 10 Januari 2012. 